\title{
PEGylated Lipid Polymeric Nanoparticle-Encapsulated Acyclovir for In Vitro Controlled Release and Ex Vivo Gut Sac Permeation
}

\author{
Syed Mahmood, ${ }^{1,2,5}$ (1) Kong Chak Kiong, ${ }^{1}$ Chun Shern Tham, ${ }^{1}$ Tan Choo Chien, ${ }^{1}$ \\ Ayah Rebhi Hilles, ${ }^{3}$ and Jayarama Reddy Venugopal ${ }^{4}$
}

Received 3 June 2020; accepted 31 August 2020; published online 14 October 2020

\begin{abstract}
Currently, pharmaceutical research is directed wide range for developing new drugs for oral administration to target disease. Acyclovir formulation is having common issues of short half-life and poor permeability, causing messy treatment which results in patient incompliance. The present study formulates a lipid polymeric hybrid nanoparticles for antiviral acyclovir (ACV) agent with Phospholipon ${ }^{\circledR}$ 90G (lecithin), chitosan, and polyethylene glycol (PEG) to improve controlled release of the drugs. The study focused on the encapsulation of the ACV in lipid polymeric particle and their sustained delivery. The formulation developed for the self-assembly of chitosan and lecithin to form a shell encapsulating acyclovir, followed by PEGylation. Optimisation was performed via BoxBehnken Design (BBD), forming nanoparticles with size of $187.7 \pm 3.75 \mathrm{~nm}, 83.81 \pm 1.93 \%$ drug-entrapped efficiency $(\mathrm{EE})$, and $+37.7 \pm 1.16 \mathrm{mV}$ zeta potential. Scanning electron microscopy and transmission electron microscopy images displayed spherical nanoparticles formation. Encapsulation of ACV and complexity with other physical parameters are confirmed through analysis using Fourier transform infrared spectroscopy, differential scanning calorimetry, and X-ray diffraction. Nanoparticle produced was capable of achieving 24-h sustained release in vitro on gastric and intestinal environments. Ex vivo study proved the improvement of acyclovir's apparent permeability from $2 \times 10^{-6}$ to $6.46 \times 10^{-6} \mathrm{~cm} \mathrm{~s}^{-1}$. Acyclovir new formulation was achieved to be stable up to 60 days for controlled release of the drugs.
\end{abstract}

KEY WORDS: acyclovir; hybrid nanoparticles (LPHNs); Box-Behnken design; in vitro; ex vivo permeation.

\footnotetext{
${ }^{1}$ Department of Pharmaceutical Engineering, Faculty of Chemical and Process Engineering Technology, University Malaysia Pahang, 26300, Gambang, Malaysia.

${ }^{2}$ Centre of Excellence for Advanced Research in Fluid Flow (CARIFF), University Malaysia Pahang, 26300, Gambang, Pahang, Malaysia

${ }^{3}$ Faculty of Health Sciences, Department of Medical Science and Technology, PICOMS International University College of Medical Sciences, 68100, Kuala Lumpur, Malaysia.

${ }^{4}$ Faculty of Industrial Sciences \& Technology, Universiti Malaysia Pahang, 26300, Gambang, Malaysia.

${ }^{5}$ To whom correspondence should be addressed. (e-mail: syedmahmood@ump.edu.my; syed872011@yahoo.co.in)

Abbreviations: $H S V 1 \& 2$, herpes simplex virus; $A C V$, acyclovir; $B S C$, Biopharmaceutical Classification System; $P L G A$, poly (lactide-coglycolides); TPP, sodium tri-phosphate; $P E G$, polyethylene glycol; $R E S$, reticuloendothelial system; $P A L N$, PEGylated acyclovir-loaded lecithinchitosan nanoparticles; $S G F$, simulated gastric fluid; $S I F$, simulated intestinal fluid; $P G$, propylene glycol; $B B D$, Box-Behnken design; $E E$, entrapment efficiency; $A L N$, acyclovir-loaded lecithin-chitosan nanoparticles; HPLC, high-performance liquid chromatography; $D A D$, photodiode array detector; $P D I$, Poly-Dispersity Index; SEM, scanning electron microscopy; HRTEM, high-resolution transmission electron microscopy; $D S C$, differential scanning calorimetry; $X R D, \mathrm{X}$-ray diffractometry; $A T R$ $F T I R$, attenuated total reflection-Fourier transform infrared.
}

\section{INTRODUCTION}

Viral diseases are emerging as a major cause for the mortality of the human life. Emergence of these infectious virus causes a pandemic and an epidemic from time to time, disturbing normal life. Virus strains and their classifications are vast, their transmission (e.g. zoonotic spread) makes them additional biologically vulnerable to human. The recent issues of the occurrence of endangered coronavirus (Covid-19) for threatening the world. Some examples of cross-species virus transmission are Ebola, severe acute respiratory syndrome (SARS), chicken pox, and herpes simplex virus (HSV). The herpes simplex virus (HSV) is from the family of Herpesvirida and mainly forms two main types (HSV-1 and HSV-2). HSV-2 infected more than 400 million people at the age of 15-59 worldwide with genital herpes with sexually transmitted and also lifelong incurable disease HSV-2 $(1,2)$. Currently, the therapeutic drugs available are acyclovir, valaclovir, and famciclovir, in which acyclovir is referred as the most widely used drug to control disease. Acyclovir (ACV) is 
acyclic guanosine analog of purine nucleoside, (guanine substituted at (2-hydroxyethoxy) methyl) at 9 position (2amino-9-(2-hydroxyethoxymethyl)-1H-purin-6-one) (2). It is mostly involved in the treatment of HSV-1 and HSV2 , given orally daily with a dose of 400 to $800 \mathrm{mg}$ (2-3) (3). In the Biopharmaceutical Classification System (BCS) class III drugs, the large dose and frequent administration are due to acyclovir having poor aqueous solubility $(1.5 \mathrm{mg} / \mathrm{mL})$ and poor permeability $(0.12 \sim 2 \times$ $\left.10^{-6} \mathrm{~cm} \mathrm{~s}^{-1}\right)$, rendering acyclovir to have low oral bioavailability $(10 \sim 30 \%)$ and short half-life $(3 \mathrm{~h})$ with molar mass $225.21 \mathrm{~g} / \mathrm{mol}$ (4-8). Oral acyclovir has a narrow absorption window, which is from the stomach to duodenum (9). The low absorption depicts the need for a delivery system that could release effectively in either or both gastric and intestinal environment to target the disease.

Several attempts have been made to enhance the delivery of oral acyclovir using polymeric mediated nanocarriers. Some of the delivery systems are interpenetrating polymeric network which is based on the close contact and molecular-scale interaction between different polymers to encapsulate the drug (10), poly (lactide-coglycolides) (PLGA) nanoparticles (2), and chitosan ionic gelation with sodium tri-phosphate (TPP) (11-14). The use of polymers and amphiphilic molecules has constantly been involved in the delivery of hydrophilic and lipophilic molecules. Lecithin (phosphatidylcholine) is used in various nanocarrier-designed formulations like micelles, liposomes, and lipid nanoparticles (15-16). Lecithin is not only used due to its safe and biocompatibility properties, but also because it is the solubilising carrier for poorly water-soluble drugs (17). Lecithin and chitosan can form spherical nanoparticle via supramolecular selforganising interaction (12). Concept of PEGylation in oral delivery is also well studied for drug release. Mariyam et al. introduced that PEGylated dendrimer-based 5fluorourasil (5FU) gave better loading and slower release of 5FU than non-PEGylated polymer (18). Moreover, the use of polyethylene glycol (PEG) imparts stealth properties on nanoparticles (19), reducing the tendency to be eliminated by the reticuloendothelial system (RES), improving bioavailability and half-life of drug (20). The hydrophilic properties of PEG could prevent interaction with other nanoparticles via sterical hindrance, improving the stability of nanoparticles (21). PEG is also claimed to enhance mucoadhesive of nanoparticles (22).

The present study aimed to design a PEGylated lipid polymeric nanoparticle system, utilising chitosan, lecithin, and poly (ethylene glycol) (PEG) 2000 that was hypothesised to produce nanoparticles with high encapsulation and good permeability, accompanied by a sustained release profile. PEGylated acyclovir-loaded lecithin-chitosan nanoparticles (PALNs) were formulated and optimised, and the physicochemical properties of PALN were characterised for stability of the nanoparticles. Simulated gastric fluid (SGF) and simulated intestinal fluid (SIF) were used to study the in vitro drug release of PALN. In contrast, rabbit intestine was used to evaluate the ex vivo permeation performance for the controlled release of the drugs for 60 days.

\section{MATERIALS AND METHODS}

\section{Materials}

Acyclovir (ACV) was acquired from Pharmaniaga Research Centre Sdn. Bhd. (Malaysia). Phospholipon ${ }^{\circledR} 90 \mathrm{G}$ (lecithin) was bought from Lipoid GmbJ, Mattermannallee, Switzerland. Chitosan, propylene glycol (PG), and polyethylene glycol (PEG-2000, MW: 1900-2200) were purchased from Merck Sdn. Bhd (USA). Dialysis bag-110 (molecular weight cut-off (MWCO): 12,000-14,000 Da) was purchased from HiMedia Laboratories Pvt. Ltd. (India). Rabbit intestinal sac was obtained as a gift from SARSHA Riding Centre. HPLCgrade Acetonitrile was procured from Fisher Scientific Inc. (Malaysia). Water is purified using a MilliQ® Integral Water Purification System with a conductivity of $15 \mathrm{M} \Omega$. Other chemicals were of analytical reagent grade.

\section{Experimental Design}

A 3-factor, 3-level, 17-run Box-Behnken Design (BBD) was adopted to generate polynomial models for the optimisation process of the drug. Three determining factors were the amount of lecithin $\left(X_{1}\right)$, chitosan $\left(X_{2}\right)$, and PEG 2000 $\left(X_{3}\right)$ as shown in Table I. Dependent variables to be optimised were entrapment efficiency (EE\%) $\left(Y_{1}\right)$, zeta potential $(\mathrm{mV})\left(Y_{2}\right)$, and particle size $(\mathrm{nm})\left(Y_{3}\right)$. DesignExpert ${ }^{\circledR}$ Software Version12 was employed to establish main effects, interaction effects, and quadratic effects from independent variables, and provide the solution for optimised formulation. The nanoparticle formulations involved, including five centre points, are tabulated in Table II. All experimental results measurement was analysed in triplicate and expressed as mean \pm standard deviation and $p<0.05$ was considered as significant for the data.

\section{Preparation of Acyclovir-Loaded Lecithin-Chitosan Nanoparticles}

ALN was prepared by the method reported by Sedef and group with little modification (15). An appropriate amount of lecithin and chitosan was weighed, as shown in Table II. Chitosan was dissolved in $15 \mathrm{~mL}$ of $0.1 \% \mathrm{v} / \mathrm{v}$ acetic acid followed by heating to $60^{\circ} \mathrm{C}$. Lecithin prepared was dissolved in an organic solvent consisting of $2.5 \mathrm{~mL}$ methanol, $2.5 \mathrm{~mL}$ chloroform, and $2 \mathrm{~mL}$ PG. An amount $15 \mathrm{mg}$ of ACV was

Table 1. Variables and Their Levels in Box-Behnken Design

\begin{tabular}{llll}
\hline Factors & \multicolumn{2}{l}{ Factor levels } & \\
\cline { 2 - 4 } & -1 (low) & 0 (medium) & +1 (high) \\
\hline A: lecithin $(\mathrm{mg})$ & 100 & 200 & 300 \\
B: chitosan $(\mathrm{mg})$ & 10 & 15 & 20 \\
C: PEG 2000 (mg) & 20 & 30 & 40 \\
Dependent variables & & Constraints \\
$Y_{1}=$ entrapment efficiency (\%EE) & & Maximise \\
$Y_{2}=$ particle size $(\mathrm{nm})$ & & Minimise \\
$Y_{3}=$ zeta potential $(\mathrm{mV})$ & & Maximise \\
\hline
\end{tabular}


Table 2. Box-Behnken Experimental Design

\begin{tabular}{llll}
\hline Formulation & \multicolumn{2}{l}{ Independent variable level } \\
\cline { 2 - 4 } & Lecithin $\left(X_{1}\right)$ & Chitosan $\left(X_{2}\right)$ & PEG 2000 $\left(X_{3}\right)$ \\
\hline PALN1 & 0 & 0 & -1 \\
PALN2 & 0 & 0 & +1 \\
PALN3 & -1 & -1 & 0 \\
PALN4 & +1 & +1 & 0 \\
PALN5 & -1 & -1 & -1 \\
PALN6 & -1 & -1 & +1 \\
PALN7 & +1 & +1 & +1 \\
PALN8 & 0 & 0 & 0 \\
PALN9 & 0 & 0 & 0 \\
PALN10 & 0 & 0 & 0 \\
PALN11 & +1 & +1 & -1 \\
PALN12 & 0 & 0 & -1 \\
PALN13 & 0 & 0 & +1 \\
PALN14 & -1 & -1 & 0 \\
PALN15 & +1 & +1 & 0 \\
PALN16 & 0 & 0 & 0 \\
PALN17 & 0 & 0 & 0 \\
\hline
\end{tabular}

added after full solubilisation of lecithin, followed by sonication to solubilise all acyclovir. The lecithin/ACV solution was then added dropwise into chitosan solution under vigorous magnetic stirring. Finally, the nano-suspension was probe sonicated for $4 \mathrm{~min}$.

\section{PEGylation of ALN}

PEGylation was performed by modifying an established method by Arya et al. (23). Prepared PEG 2000 solutions were $200 \mathrm{mg} / \mathrm{mL}, 300 \mathrm{mg} / \mathrm{mL}$, and $400 \mathrm{mg} / \mathrm{mL}$. One millilitre of the solution was added into nano-suspension formed under Section C. The suspension was agitated at moderate intensity for $30 \mathrm{~min}$, followed by probe sonication with $30 \%$ amplitude, pulse on/off the rate of $10 \mathrm{~s} / 5 \mathrm{~s}$, for 2 cycles. The formulated particles were centrifuged and supernatants containing any trace of free ACV were separated for the purification of drug. Final product PEGylated ACV-loaded lecithin/chitosan Nanoparticles (PALNs) were stored for further analysis to study the controlled release of drugs.

\section{Optimisation of Formulation}

\section{Drug Entrapment Efficiency Analysis}

Amount of encapsulated ACV in nanoparticles was identified indirectly in high-performance liquid chromatography (HPLC) (24). Agilent 1260 Series HPLC system fitted with a photodiode array detector (DAD), and use Thermo Fisher Syncronis C-18 $(5-\mu \mathrm{m}$ particle size, $150 \times 4.60 \mathrm{~mm}$ diameter) column. A fixed injection volume of $20 \mu \mathrm{l}$ per sample, a column temperature of $25^{\circ} \mathrm{C}$, and a wavelength of $254 \mathrm{~nm}$ were set. The mobile phase used was acetonitrile and pH 6.74 water $(10: 90, \mathrm{v} / \mathrm{v})$, which was set at an isocratic flow rate of $0.5 \mathrm{ml} / \mathrm{min}$ for 10 -min run time. Equation (1) showed a calibration curve that fit over the range $100-500 \mu \mathrm{g} / \mathrm{ml}$ with a correlation coefficient of $r^{2}=0.99990$. $y=117.88803 x+43.82506$

where $y$ represented the peak area in a milli-absorbance unit $(\mathrm{mAu})$ and $x$ represented the ACV concentration $(\mathrm{mg} / \mathrm{ml})$.

In evaluating the entrapment efficiency (EE), PALNs prepared were stored in $-80^{\circ} \mathrm{C}$ freezer for $24 \mathrm{~h}$. Then PALNs were thawed and isolated by centrifugation at $48,000 \times \mathrm{g}$ at $4{ }^{\circ} \mathrm{C}$ for $20 \mathrm{~min}$. The supernatants consisted of the free drug were:

$E E(\%)=\left(M_{\text {total }}-M_{\text {free }}\right) / M_{\text {total }} 100 \%$

where EE was the entrapment efficiency, and $M_{\text {total }}$ and $M_{\text {free }}$ were a total mass of ACV added and free ACV in supernatant respectively.

\section{Zeta Potential Measurement Particle Size and Poly-Dispersity Index}

Particle size, Poly-Dispersity Index (PDI), and zeta potential were determined by DelsaMax PRO Zeta Potential Dynamic Light Scattering Analyzer (Beckman Coulter, USA). To measure the size and zeta potential, $0.1 \mathrm{ml}$ of prepared particles was diluted with $2.0 \mathrm{ml}$ of deionised water loaded in flow cell and scanned for particles. The measurement was done in a $173^{\circ}$ scattering angle. The experiment was done with a setting of $25 \pm 0.5^{\circ} \mathrm{C}$.

\section{Characterisation of Optimised PALN Formulation}

\section{Morphological Analysis}

Morphology study of the nanoparticles was carried out using scanning electron microscopy (SEM) (4). The formulation was lyophilised and further dried using vacuum oven for $30 \mathrm{~min}$ and the powder was uniformly spread on the coverslip and further coated with platinum using 208HR HighResolution Sputter Coater (Ted Pella, INC, CA, USA). Coated sample was then inserted into the specimen chamber and scanned using TM 3030 Plus scanning electron microscope (Hitachi, Tokyo, Japan), at $5 \mathrm{kV}$.

\section{High-Resolution Transmission Electron Microscopy}

The optimised formulation was visualised by highresolution transmission electron microscopy (HRTEM). The formulation was diluted with water in ratio of (1:50) and placed on the copper film-coated grid, with a diameter of $3.05 \mathrm{~mm}$ and $400 \mathrm{mesh}$ size (Ted Pella, CA, PELCO® 400 Mesh Grids). After placing the particle, they were air dried for $15 \mathrm{~min}$ and any access of water was removed using a filter paper. The analysis was done by using a Tecnai G2 20 Twin transmission electron microscope (FEI Company, Oregon, USA).

\section{Differential Scanning Calorimetry}

Thermal properties of optimised formulation were analysed using differential scanning calorimetry (DSC) 214 Polyma differential scanning calorimeter (NETZSCG- 
Gerätebau GmbH, German). Samples used included lecithin, chitosan, PEG 2000, optimised formulation, pure acyclovir, and a blend of acyclovir, chitosan, lecithin and PEG 2000 (physical mixture, PM). The optimised formulation was dried in SHEL LAB SVAC2-2 vacuum oven (Sheldon Manufacturing Inc., USA) under $35^{\circ} \mathrm{C}$ and 25 in. Mercury $(\mathrm{Hg})$ before analysis (16). Black alumina was used as a reference. Nitrogen gas purge rate was $20 \mathrm{~mL} / \mathrm{min}$. The analysis was conducted with settings shown in Table III. All the scanned samples were analysed in triplicate to plot the data.

\section{X-Ray Diffractometry}

The crystallinity of PALNs synthesised was studied through the sharpness of peak in the XRD spectra by $X^{\prime}$ Pert $^{3}$ Powder X-Ray Diffractometer with X'Celerator (Malvern Panalytical, UK). Samples used were lyophilised PALNs, pure ACV, and PM. Samples were radiated with $\mathrm{CuK} \alpha$ radiation at $45 \mathrm{kV}$ and $140 \mathrm{~mA}$. $2 \theta$ scan range from $0^{\circ}$ to $60^{\circ}$, with $3^{\circ} / \mathrm{min}$ scanning rate, and $0.05^{\circ}$ step size were set (17). All the tests were performed in triplicates.

\section{Attenuated Total Reflection-Fourier Transform Infrared Spectrometer}

Compatibility study was conducted using Nicolet iS50 FT-IR Spectrometer (Thermo Fisher Scientific Inc., Waltham, MA). Samples used included pure acyclovir, lecithin, chitosan, PEG 2000, optimised formulation, and PM. Before analysis, optimised formulation was vacuum-dried at $35^{\circ} \mathrm{C}$ and -25 in $\mathrm{Hg}(17)$. The analysis was done with sixteen scans at scanning range of 600 to $4000 \mathrm{~cm}^{-1}$.

\section{Stability Study}

A replicate of optimised PALN was prepared without lyophilisation and assessed for short-term physical stability for 60 days based on ICH guidelines. The sample was stored in $4^{\circ} \mathrm{C}$ chiller throughout the study period. Nanoparticle size of the sample was measured by using the method as described in section $\mathrm{F}$ at an interval of 0th, 15th, 30th, 45th, and 60th days. A $p<0.05$ was considered as significant for the obtained data.

Table 3. DSC Setting for Thermal Analysis of Each Sample

\begin{tabular}{llll}
\hline Sample & \multicolumn{2}{l}{ Heating range $\left({ }^{\circ} \mathrm{C}\right)$} & Heating rate $\left({ }^{\circ} \mathrm{C} / \mathrm{min}\right)$ \\
\cline { 2 - 3 } & Initial & Final & \\
\hline Optimised formulation & 0 & 320 & 5 \\
Lecithin & 10 & 100 & 3 \\
Chitosan & 50 & 320 & 10 \\
PEG 2000 & 0 & 320 & 10 \\
Acyclovir & 50 & 320 & 10 \\
Physical mixture & 0 & 320 & 10 \\
\hline
\end{tabular}

\section{In Vitro Drug Release Profile}

In vitro drug release profile was conducted on the optimised formulation by employing a dialysis bag method with USP apparatus II. Two sets of dialysis bag (MWCO: $14,000 \mathrm{Da})$ of suitable length to accommodate the sample were prepared and immersed in $37^{\circ} \mathrm{C}$ ultrapure water for $30 \mathrm{~min}$ for stabilisation. One end of the dialysis bags was tied securely with thread. Then $4 \mathrm{~mL}$ of optimised formulation with ACV concentration of $1 \mathrm{mg} / \mathrm{mL}$ was injected into each dialysis bag. Another end of the dialysis bags was then tied securely with a thread. The dialysis bags were kept in sink condition in two separated vessels of a RC-8DS dissolution tester (Sinopham Co., Ltd., China) filled with $400 \mathrm{~mL}$ of pH 1.2 hydrochloric acid buffer (SGF) and $400 \mathrm{~mL}$ of $\mathrm{pH} 6.4$ phosphate buffer saline (SIF) respectively. Dissolution tester was set for $70-\mathrm{rpm}$ rotation and $37^{\circ} \mathrm{C}$ water bath. One millilitre of sample was taken in triplicate at $0.5 \mathrm{~h}, 1 \mathrm{~h}, 2 \mathrm{~h}$, $4 \mathrm{~h}, 8 \mathrm{~h}, 12 \mathrm{~h}$, and $24 \mathrm{~h}$. The same volume of fresh medium was re-filled into the corresponding vessel. Samples were analysed with HPLC method as described in section E. Another calibration curve with a smaller range from (1) was generated to ensure the accuracy of ACV concentration derived from peak area. Equation (3) showed a calibration curve that fit over the range of 5 to $50 \mu \mathrm{g} / \mathrm{mL}$ with $r^{2}$ of 0.99964 .

$y=125.32389 x+79.70511$

The drug release profile of optimised formulation was plotted with a cumulative percentage of ACV released against time. Drug release data was fitted into one of the releasing models which were zero order, first order, Higuchi, Korsmeyer-Peppas, and Hixson-Crowell releasing model. A best model kinetic fit describing drug release of the formulation was selected according to the coefficient of determination $\left(r^{2}\right)$ that calculated with aid from Microsoft Excel. Equation (4) was used as a formula for the cumulative percentage of drug-released calculation.

$D R(\%)=\left(M_{\text {released }} / M_{\text {total }}\right) 100 \%$

where DR was the cumulative percentage of drug released, and $M_{\text {released }}$ and $M_{\text {total }}$ were mass of acyclovir released and total mass of acyclovir in formulations used respectively.

\section{Study of Ex vivo Intestinal Permeability}

Ex vivo study was performed according to an established method (25) with modification. The study was done using New Zealand white rabbit of age 5-6 months. The rabbit intestine sac was cleaned with cold saline. It was cut into several 9.5-cm-long segments. The intestine segment was tied up securely with thread at one end, followed by the introduction of $2 \mathrm{~mL}$ of optimised formulation with $1 \mathrm{mg} /$ $\mathrm{mL}$ of ACV concentration into the intestinal opening. The other end was then tied up securely with thread. The rabbit intestine sac containing the formulation was kept in sink condition in a beaker containing $80 \mathrm{~mL}$ of $\mathrm{pH} 7.4$ PBS with $1 \% \mathrm{~m} / \mathrm{v}$ sodium lauryl sulphate $(\mathrm{SLS})$ at $37^{\circ} \mathrm{C}$ as releasing 
medium. The beaker was closed with cover to prevent evaporation of releasing medium. One millilitre of the sample was taken at $0.5 \mathrm{~h}, 1 \mathrm{~h}, 2 \mathrm{~h}, 4 \mathrm{~h}, 6 \mathrm{~h}, 8 \mathrm{~h}$, and $10 \mathrm{~h}$ in triplicate, and an equal amount of fresh releasing medium was replenished. Samples were analysed with HPLC method as described in section E, and Eq. (3) was used for calculation of ACV concentration in the samples.

Drug intestinal permeability profile of optimised PALN formulation was plotted with a cumulative amount of ACV permeated into releasing medium against time. Cumulative percentage of drug permeated was calculate with Eq. (5)

$D P(\%)=\left(M_{\text {medium }} / M_{\text {total }}\right) 100 \%$

where DP was the cumulative percentage of drug permeated and $M_{\text {medium }}$ was the mass of acyclovir in releasing medium.

Apparent permeability of the formulation as a function of the mucosal surface area was calculated by Eq. (6). In contrast, Eqs. (7) and (8) were used to calculate apparent permeability coefficient and steady-state flux, and $J_{\text {ss }}$ of acyclovir in formulation, respectively.

Apparentpermeability $\left(\mathrm{mgcm}^{-2}\right)$

$=M_{\text {medium }} /$ MucosalSurfaceArea $\left(\mathrm{cm}^{2}\right)$

$P_{\text {app }}\left(c m s^{-1}\right)=(d Q / d t) 1 /\left(A C_{0}\right)$

where $P_{\text {app }}$ was the apparent permeability coefficient, $\mathrm{dQ} / \mathrm{dt}$ was the slope for the graph of the cumulative amount of ACV permeated against time in unit of $\mathrm{mg} / \mathrm{h}, A$ is the surface area of intestinal tissue where the permeation of nanoparticles occurred in the unit of $\mathrm{cm}^{2}$, and $C_{0}$ gave an initial concentration of $\mathrm{ACV}$ in the intestinal sac that was $1 \mathrm{mg} / \mathrm{mL}$ (equivalent to $1 \mathrm{mg} / \mathrm{cm}^{3}$ ).

$J_{s s}\left(m g c m^{-2} s^{-1}\right)=P_{a p p} C_{0}$

\section{RESULTS AND DISCUSSION}

\section{Mechanism of PALN Formation}

PEGylated lipid polymeric nanoparticle (PALN) formation hypothesis is shown Fig. 1. The method follows the selforganising interaction between the combination of lecithin, chitosan, and PEG 2000 (15). ACV, being polar in nature, attracts the hydrophilic head of lecithin (26), while randomly dispersing in the solvent for fabricating nanoparticles. The lecithin/ACV solution was added into chitosan solution, the electrostatic interaction between chitosan, and lecithin led to the formation of chitosan hydrophilic shell layer surrounding the internal core of lecithin and ACV. The combination of chitosan and lecithin permitted the formulation of stiff and stable nanostructure (27). Hydrogen bonding and physical entanglement might also occur between lecithin and chitosan (28).

PEG can provide stealth property on nanoparticles to avoid RES elimination and prolong their circulation time (29). Protonation on chitosan-free amino group in the acidic environment caused it to be positively charged. The dipoledipole or hydrogen bonding between chitosan shell and PEG became stronger than intra-molecular or intermolecular hydrogen bonding of chitosan chain and allowed PEG grafting onto it due to interaction between amine or amide nitrogen of chitosan, and hydroxyl and etheric oxygen of PEG (30). Probe sonication was employed to reduce particle size as well as improving uniformity of size. PALNs formulated exhibited a pale white appearance with soapy texture. Pale white colour resulted from the massive amount of nanoparticles formed, while the frothy white texture was due to the presence of PEG 2000 in the formulation.

\section{Optimisation of Formulation}

The Box-Behnken design with $3 \times 3$ factorial design generated 17 trail with 5 centre points runs for the preparation of PEGylated lipid polymeric nanoparticles (PALNs) as shown in Table II. The optimisation data shows that the concentration of independent factors lecithin (A), chitosan (B), and PEG 2000 (C) exerts an individual negative and positive effect on the dependent factors i.e. entrapment efficiency (Y1), particle size (Y2), and zeta potential (Y3). The best fitted equation was selected as quadratic for all the 3 dependent factors. The effect was shown through 3D response surface depicting the interaction between independent variables and dependent factors as shown in Fig. 2. Before the BBD development, some preliminary studies were conducted using the ratio of the lecithin and chitosan was selected. The aim was to get the maximum entrapment efficiency and minimum range for particle size. The probe sonication was selected at $4 \mathrm{~min}$, as in our preliminary studies, it was concluded that high sonication with leaded to breakage in the particle and 1--2-min sonication produced particles with large diameters.

\section{Drug Entrapment Efficiency}

The EE is shown in Table IV and Fig. 2 a represented the graphical presentation of EE for all formulations. The results obtained for the drug EE ranged from 68 to $87 \%$. The use of sonication for solubilisation of ACV in organic solvent allowed it to be correctly attached to lecithin and get encapsulated into nanoparticles formed.

Design-Expert software generated Eq. (9) that expressed the effect from independent factors, which were the amount of lecithin $\left(\mathrm{X}_{1}\right)$, amount of chitosan $\left(\mathrm{X}_{2}\right)$, and amount of PEG $2000\left(X_{3}\right)$ on drug entrapment efficiency of the formulation.

$$
\begin{aligned}
Y_{1}= & 85.44+3.57 X_{1}-3.83 X_{2}-2.04 X_{3}-2.02 X_{1} X_{2}+1.19 X_{1} X_{3}-1.95 X_{2} X_{3}-6.91 X_{1}^{2}- \\
& 4.34 X_{2}^{2}-0.19 X_{3}^{2}
\end{aligned}
$$

A positive value for coefficient indicates the increment in the factor results in an appropriate improvement in the 


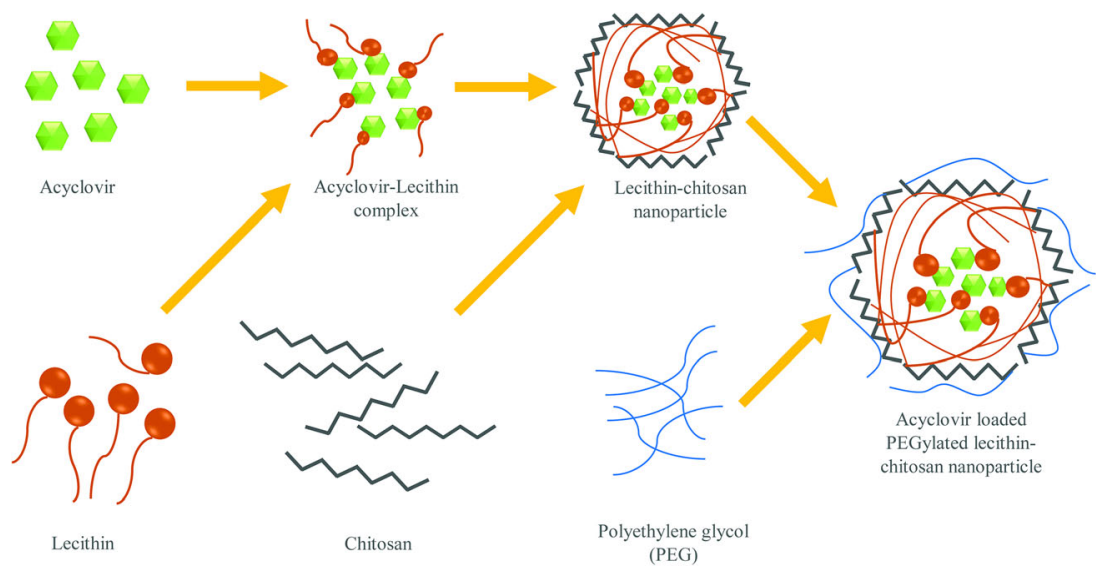

Fig. 1. Schematic diagram for PALNs formation. a Hydrophilic head attracts towards the polar head. b Lecithin-chitosan leads to electrostatic interaction and formation assembly. $\mathbf{c}$ Self-organisation between the lecithin, chitosan, and PEG 2000

response and vice versa. The equation with adjusted $R^{2}$ of 0.9398 indicates a good fit. Interaction between the factors affecting drug entrapment efficiency was as shown in Fig. 3 ac; it is to be noted that the $\mathrm{X} 1$ and $\mathrm{X} 2$ in the figures indicate the $\mathrm{X}$-axis instead of the independent factors.

Figure 3 a showed the increment of drug entrapment efficiency by increasing lecithin amount and decreasing chitosan. It is also observed that drug entrapment efficiency reduced at level 1 of lecithin, as micelle formed when lecithin concentration exceeds critical micelle concentration which could affect the encapsulation process. Lowering the amount of lecithin also led to poor encapsulation efficiency as less available hydrophilic heads to be attracted by ACV (26). Increment in chitosan concentration amount improved selfassembling process between chitosan and lecithin, which also resulted in weakly attraction between ACV and lecithin and ACV will not be entrapped. It is noticed that the interaction effects between lecithin and chitosan have the most substantial impact on entrapment efficiency.

Figure $3 \mathrm{~b}$ and $\mathrm{c}$ showed the interaction between PEG 2000 as well as between chitosan and lecithin on entrapment efficiency was weaker when compared with lecithin and chitosan. EE decreases slightly with an increment of PEG 2000 amount, which might be due to the interaction between the PEG 2000 and chitosan, as it affects the electrostatic interaction between lecithin and chitosan, causing the tight junction to be disrupted upon mixing, resulting in drug leaking. The disruption was attributed to the ability of PEG 2000 to enter the loosely packed structure (31). A suitable amount of lecithin $\left(\mathrm{X}_{1}\right)$ should be used in pair with sufficient but not excessive amount of chitosan $\left(\mathrm{X}_{2}\right)$, and less PEG 2000 $\left(\mathrm{X}_{3}\right)$ for high EE.

\section{Zeta Potential Measurements}

Zeta potential for all formulations was determined and tabulated in Table IV as observed values. Figure $2 \mathrm{~b}$ showed the graphical presentation of zeta potential measurement for 17 formulations. The zeta potential ranged from $+20.77 \pm 5.59$ to $+50.4747 \pm 1.65 \mathrm{mV}$. The zeta potential was mainly determined by lecithin and chitosan used. However, PEG 2000 as a polymer grafting on the lecithin-chitosan core-shell structure might be impacting the stability of the nanoparticle. The values can be used as an indicator that all the prepared hybrid nanoparticle formulations were highly stable. Using Design-Expert software, the relationship between the used amount of lecithin, chitosan, and PEG 2000 on zeta potential can be explained using Eq. (10) with a high $R^{2}$ value of 0.9294 .

$$
\begin{aligned}
Y_{2}= & 28.09-3.57 X_{1}+8.68 X_{2}-7.16 X_{3}+0.42 X_{1} X_{2}+1.83 X_{1} X_{3}+2.08 X_{2} X_{3}+1.51 X_{1}^{2}+ \\
& 6.7 X_{2}^{2}+1.84 X_{3}^{2}
\end{aligned}
$$

Figure $3 \mathrm{~d}$ showed positive linear relationship between zeta potential and amount of chitosan used for developing the nanoparticles. The relationship was predictable since chitosan dissolves in an aqueous solvent, exhibiting net positive charges due to the protonated amine group (30). When the amount of lecithin used decreases, the zeta potential increases, proving that negatively charged lecithin had reacted with positively charged chitosan, producing a negative effect on zeta potential. The same trend can be seen in Fig. 3 e, where PEG 2000 with a surface charge of -2 to $7 \mathrm{mV}$ also had a negative effect on zeta potential, but to a lower extent to that of lecithin (32). It can be seen that chitosan was capable of producing formulation with zeta potential greater than $50 \mathrm{mV}$. Still, the use of PEG 2000 and lecithin, or to be exact, the electrostatic interaction between chitosan and other components, causes the reduction of zeta potential. Figure $3 \mathrm{f}$ further supported the point that lecithin and PEG 2000 were responsible for zeta potential decrement. When a higher proportion of PEG2000 (40 mg) and lecithin (300 mg) was used, the zeta potential significantly decreases in the nanoparticles.

\section{Particle Size and PDI Analysis}

Particle size and PDI obtained from all 17 formulations were recorded in Table IV as observed values and illustrated in Fig. 2 c. The particle size ranged from $155.31 \pm 6.87$ to $264.82 \pm 4.33 \mathrm{~nm}$, with PDI ranged from $0.179 \pm 0.03$ to 0.429 \pm 0.12 . In overall, the results were accepted as it is capable of 

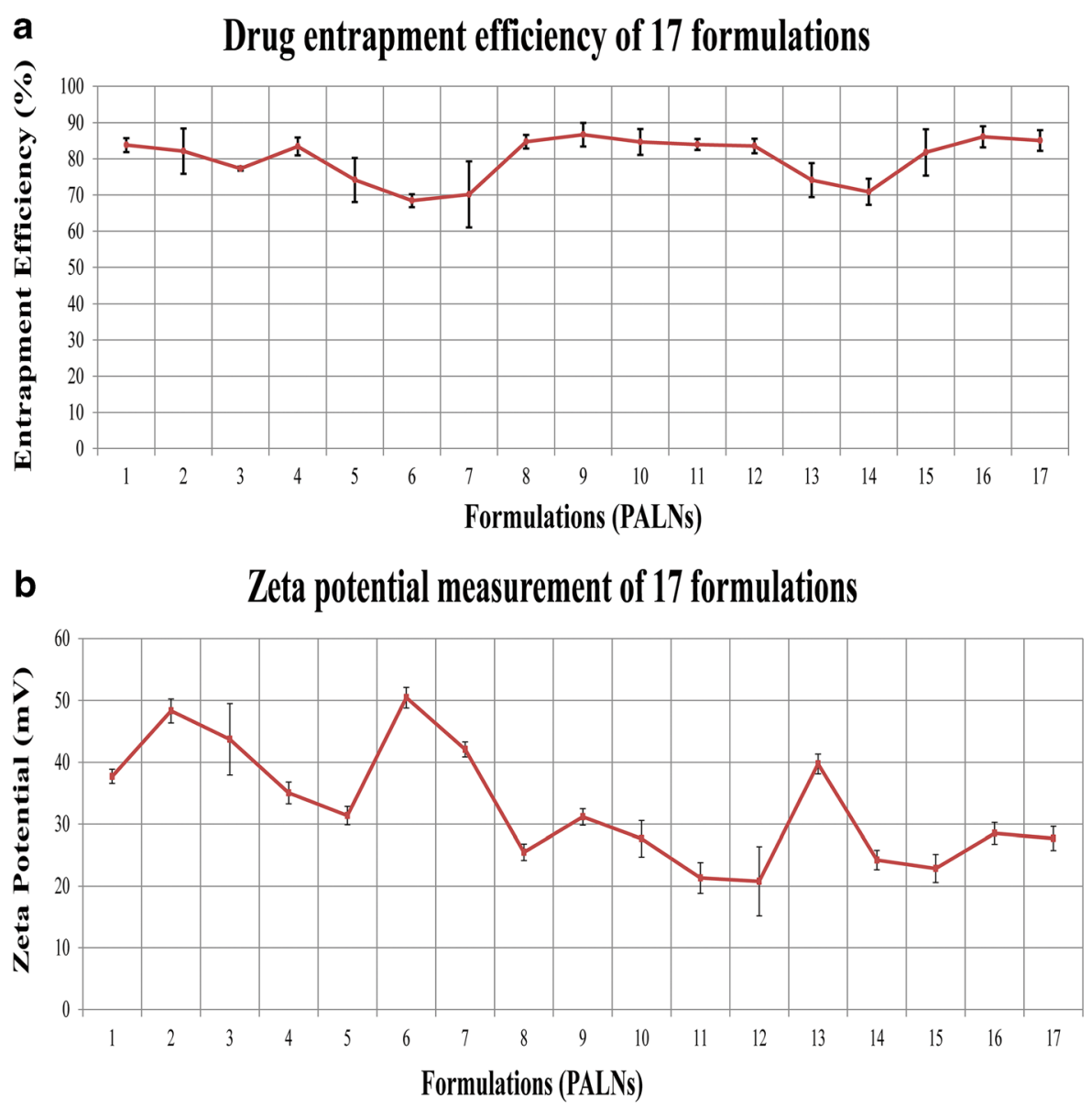

c Particle size and PDI measurement of 17 formulations

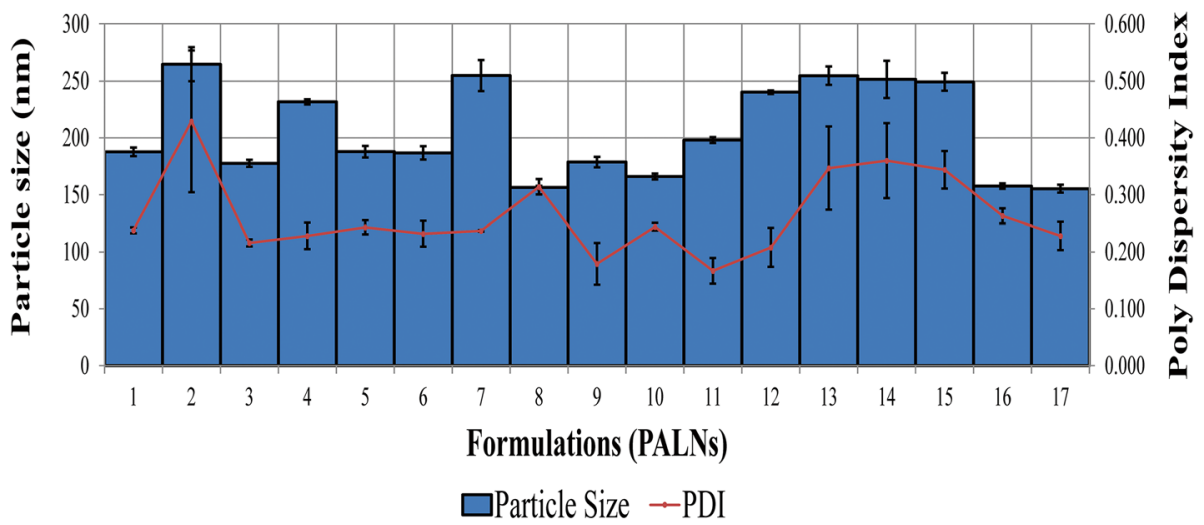

Fig. 2. Graphical presentation of a drug entrapment efficiency, $\mathbf{b}$ zeta potential, and $\mathbf{c}$ particle size and PDI PALNs formulation

exhibiting enhanced permeability and retention (EPR) effect. Equation (11) describes the effect of three independent factors on particle size, with high $r^{2}$ value of 0.9162 to prove that the equation is reliable.

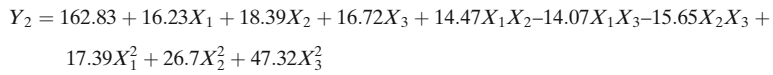

We observed that particle size was significantly impacted by amount of lecithin, chitosan, and PEG 2000 used, as shown in Fig. $3 \mathrm{~g}-\mathrm{i}$.
The particle size of PALN increased with the amount of lecithin and chitosan used in the nanoparticles. As more lecithin and chitosan were used, more drugs attracted and entrapped in the core, forming bulkier nanoparticle. The nanoparticles formed showed a size smaller than $200 \mathrm{~nm}$, as a proven larger proportion of smaller nanoparticle size area in Fig. 4. To decrease the amount of chitosan injudiciously was not preferred as it might be insufficient to form a complete spherical structure with lecithin, which was bulkier with attached drug. Thus, lecithin to chitosan ratio must be adjust to ensure complete self-assembling process as it leads to rigid spherical nanoparticle occupying less space. On the other 
Table 4. Observed and predicted value of encapsulation efficiency $\left(Y_{1}\right)$, particle size $\left(Y_{2}\right)$ and zeta potential $\left(Y_{3}\right)$ of formulations in the Box-Behnken design

\begin{tabular}{|c|c|c|c|c|c|c|c|}
\hline \multirow[t]{2}{*}{ Sample } & \multicolumn{2}{|l|}{$\mathrm{EE}, \%\left(Y_{1}\right)$} & \multicolumn{2}{|c|}{ Zeta potential, $\mathrm{mV}\left(Y_{2}\right)$} & \multicolumn{2}{|c|}{ Particle size, $\mathrm{nm}\left(Y_{3}\right)$} & \multirow[t]{2}{*}{ PDI } \\
\hline & Observed & Predicted & Observed & Predicted & Observed & Predicted & \\
\hline PALN1 & $83.81 \pm 1.93$ & 84.84 & $37.70 \pm 1.16$ & 37.19 & $187.7 \pm 3.75$ & 186.09 & $0.238 \pm 0.01$ \\
\hline PALN2 & $82.15 \pm 6.26$ & 81.07 & $48.33 \pm 1.93$ & 50.39 & $264.8 \pm 12.21$ & 254.17 & $0.429 \pm 0.12$ \\
\hline PALN3 & $77.28 \pm 0.58$ & 78.00 & $43.73 \pm 5.78$ & 44.00 & $177.7 \pm 5.23$ & 180.51 & $0.216 \pm 0.01$ \\
\hline PALN4 & $83.44 \pm 2.47$ & 82.77 & $35.03 \pm 1.76$ & 33.20 & $231.7 \pm 6.32$ & 241.17 & $0.228 \pm 0.02$ \\
\hline PALN5 & $74.17 \pm 6.10$ & 72.42 & $31.37 \pm 1.48$ & 31.60 & $187.9 \pm 9.56$ & 186.76 & $0.243 \pm 0.01$ \\
\hline PALN6 & $68.45 \pm 1.79$ & 68.81 & $50.47 \pm 1.65$ & 48.13 & $186.8 \pm 8.98$ & 194.69 & $0.232 \pm 0.02$ \\
\hline PALN7 & $70.17 \pm 9.14$ & 71.92 & $42.07 \pm 1.21$ & 41.83 & $254.8 \pm 15.45$ & 256.00 & $0.237 \pm 0.00$ \\
\hline PALN8 & $84.72 \pm 1.90$ & 85.44 & $25.47 \pm 1.33$ & 28.09 & $156.4 \pm 8.98$ & 162.83 & $0.314 \pm 0.01$ \\
\hline PALN9 & $86.67 \pm 3.27$ & 85.44 & $31.17 \pm 1.33$ & 28.09 & $178.7 \pm 10.54$ & 162.87 & $0.179 \pm 0.03$ \\
\hline PALN10 & $84.67 \pm 3.56$ & 85.44 & $27.63 \pm 2.94$ & 28.09 & $166.1 \pm 3.65$ & 162.87 & $0.244 \pm 0.01$ \\
\hline PALN11 & $83.97 \pm 1.52$ & 83.61 & $21.30 \pm 2.48$ & 23.63 & $198.1 \pm 4.78$ & 190.29 & $0.167 \pm 0.02$ \\
\hline PALN12 & $83.57 \pm 2.03$ & 84.64 & $20.77 \pm 5.59$ & 18.70 & $240.2 \pm 4.56$ & 250.82 & $0.208 \pm 0.03$ \\
\hline PALN13 & $74.13 \pm 4.69$ & 73.10 & $39.73 \pm 1.60$ & 40.24 & $254.7 \pm 16.87$ & 256.30 & $0.347 \pm 0.07$ \\
\hline PALN14 & $70.86 \pm 3.61$ & 71.53 & $24.20 \pm 1.56$ & 26.02 & $251.5 \pm 24.56$ & 242.08 & $0.360 \pm 0.07$ \\
\hline PALN15 & $81.77 \pm 6.41$ & 81.06 & $22.83 \pm 2.28$ & 22.55 & $249.2 \pm 16.87$ & 246.42 & $0.344 \pm 0.03$ \\
\hline PALN16 & $86.09 \pm 2.93$ & 85.44 & $28.49 \pm 1.76$ & 28.10 & $157.5 \pm 3.45$ & 162.83 & $0.263 \pm 0.01$ \\
\hline PALN17 & $85.06 \pm 2.88$ & 85.44 & $27.69 \pm 1.97$ & 28.10 & $155.3 \pm 7.65$ & 162.82 & $0.228 \pm 0.02$ \\
\hline
\end{tabular}

hand, increment in PEG 2000 thickens the layer on PALN, resulting in size increment (32). It is also observed that without sufficient PEG 2000, the drug residence time in systemic blood circulation might not be able to be significantly prolonged for nanoparticles.

\section{Statistical Analysis of Experimental Data by Design-Expert Software}

Table V summarised quadratic equation used in describing the effect of three independent variables on three dependent variables. All factor with $(p$ value $<0.05)$ were considered as significant. The expected values for $Y_{1}, Y_{2}$, and $Y_{3}$ was shown in Table IV. Due to negligible difference between observed and predicted value, a quadratic Eqs. (9), (10), and (11) can serve as a good indicator of behaviour and interaction relationship between the independent factors.

The measurements considering for all obtained and software's recommendation, formulation PALN1 with high EE of $83.81 \pm 1.93 \%$, the particle size of $187.7 \pm 3.75 \mathrm{~nm}$, and PDI of $0.238 \pm 0.01$. The values of PALN1 were selected due to its higher EE and optimum size. The zeta potential of + $37.70 \pm 1.16 \mathrm{mV}$ of PALN1 was found to be very stable. The ratio of lecithin to chitosan for the optimised formulation is exactly 20:1, which was known to be the perfect proportion of both materials to get a small-sized nanoparticle with spherical shape (33).

\section{Characterisation of Optimised Formulation}

\section{Scanning Electron Microscopy}

The SEM images revealed a round and spherical shape morphology with a smooth surface of the nanoparticles (Fig. $4 a, b)(34)$.

\section{High-Resolution Transmission Electron Microscopy}

Figure $4 \mathrm{c}$ shows the range of particle size from 172 to $198 \mathrm{~nm}$. The HRTEM measurement was in the agreement with dynamic light scattering (DLS) measurement of PALN1 particle size of $187.7 \pm 3.75 \mathrm{~nm}$. Also, the figure shows a twolayer structure of nanoparticles, which corresponds to the formation of chitosan shell layer around the lecithin core (35).

\section{Differential Scanning Calorimetry}

Figure 5 a lecithin showed a low-intensity endothermic peak at $47.2^{\circ} \mathrm{C}$, which was the chain melting transition point where it transformed into a liquid crystalline form from a gel form with enhanced ability to act as a drug carrier (36). Two endotherms were observed for chitosan, where $83.8^{\circ} \mathrm{C}$ was attributed to water loss and polymeric chain decomposition at $303.7^{\circ} \mathrm{C}$ (37). PEG 2000 endothermic peaks at $53.5^{\circ} \mathrm{C}$, indicating melting process of the sample (36).

ACV had four thermal effects shown in Fig. 5 a. The analysis for ACV used was ACV polymorph form VI, with 1:2 ratio of $\mathrm{ACV}$ to water. The first endothermic peak at $116.5^{\circ} \mathrm{C}$ was assigned to the dehydration process. It leads to recrystallisation of $\mathrm{ACV}$ form $\mathrm{VI}$ to $\mathrm{ACV}$ form $\mathrm{V}$, which undergoes a phase transition to IV at $174.6^{\circ} \mathrm{C}$. Further heating leads to endotherm at $255.7^{\circ} \mathrm{C}$, indicating $\mathrm{ACV}$ melting point (MP). Last exothermic peak at $259.1^{\circ} \mathrm{C}$ was assigned to the exothermic decomposition of the ACV (38).

The physical mixture for the first endotherm was assigned to the lecithin and PEG2000. ACV endothermic peak diminished but a new peak emerged at $151^{\circ} \mathrm{C}$. It might be due to molecular interaction between drug, lecithin and chitosan. The interaction causes ACV to have decreased crystallinity and increased amorphous properties of acyclovir, or turned into semi-solid form, or dissolution in the matrix melt (39). For PALN1, peak diminishments of lecithin, 

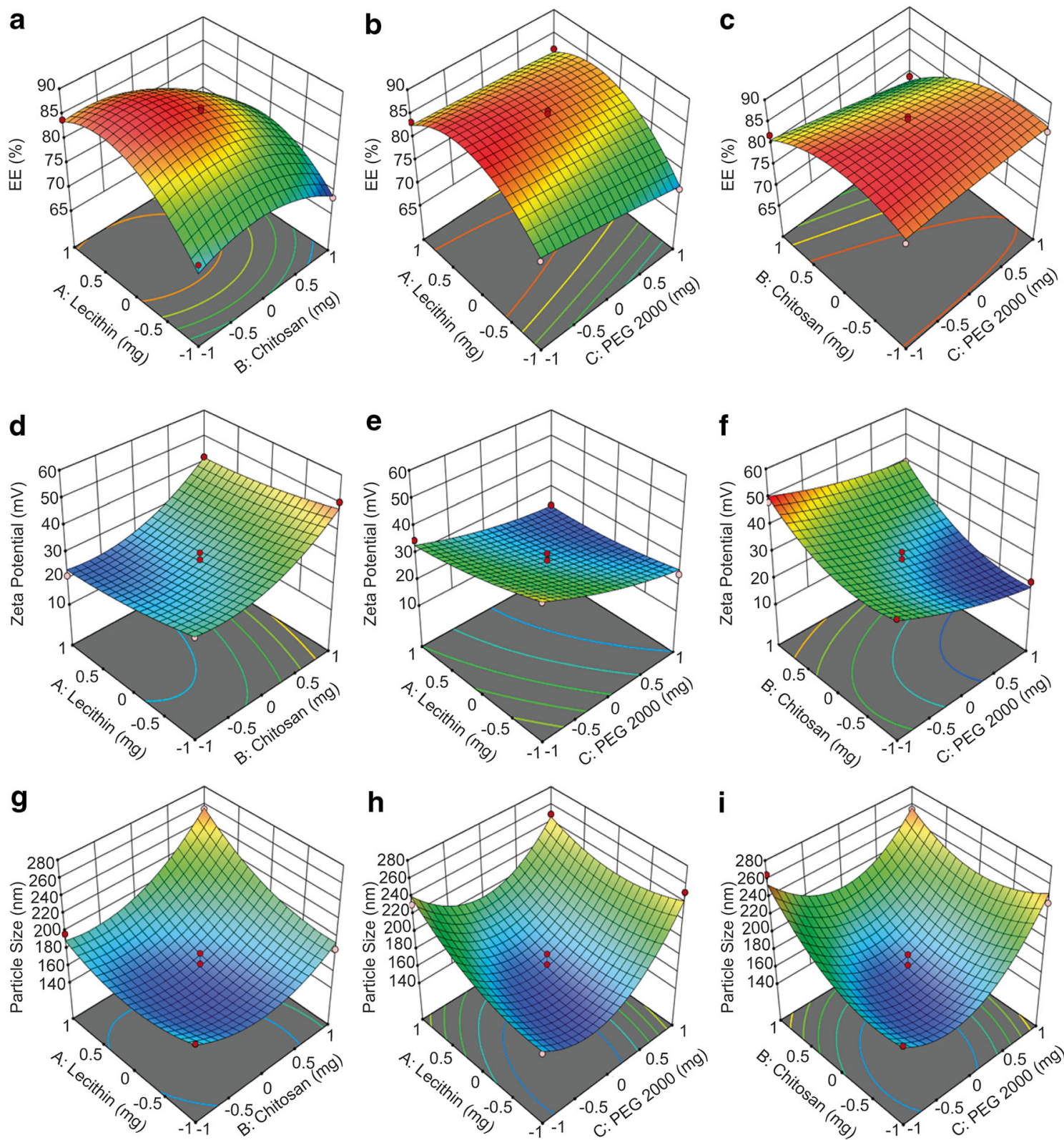

Fig. 3. Three-dimensional (3-D) response surface plot showing effect of the independent factors on the depended responses $\mathrm{EE} \%$, particle size, and zeta potential

chitosan, and PEG 2000 were observed. An endotherm observed at $242.3^{\circ} \mathrm{C}$ was assigned to the left shift of the ACV MP. Although the left shift was evidence for crystallinity changes, the amplitude of shifting was abnormal. Table III showed that heating rate for acyclovir and PM was higher than PALN1. Higher heating rate results in MP shifted to a higher temperature which is in agreement from the previous report of acyclovir MP (40).

\section{X-Ray Diffraction}

Figure $5 \mathrm{~b}$ showed the ACV peaks at $2 \theta$ of $7.12^{\circ}, 10.66^{\circ}$, $13.22^{\circ}, 16.19^{\circ}, 23.56^{\circ}, 24.10^{\circ}, 26.33^{\circ}$, and $29.44^{\circ}$, indicating crystalline nature of the drug. Crystallinity index was calculated based on (12) with the aids of OriginPro Graphing \& Analysis 2020 software. The ACV crystalline and total peak area were found to be 53,181.75 and 56,443.52 unit area, respectively, with crystallinity index calculated to be 0.9422 , which was very crystalline

CrystallinityIndex $=$ Area $_{\text {Crystalline }} /$ Area $_{\text {Total }}$

where Area $_{\text {Crystalline }}$ and Area Total $_{\text {were integrated areas for }}$ crystalline structure and total integrated area, respectively.

ACV peak was diminished from PM diffractogram. This suggested possibility of ACV turned into the disordered crystalline state due to the molecular interaction with lecithin and chitosan. By comparing ACV and PALN1 diffractogram, a broad peak emerged with sharp peak diminishment indicating ACV entrapped in LPNPs system in the amorphous state of the nanoparticles (41). 

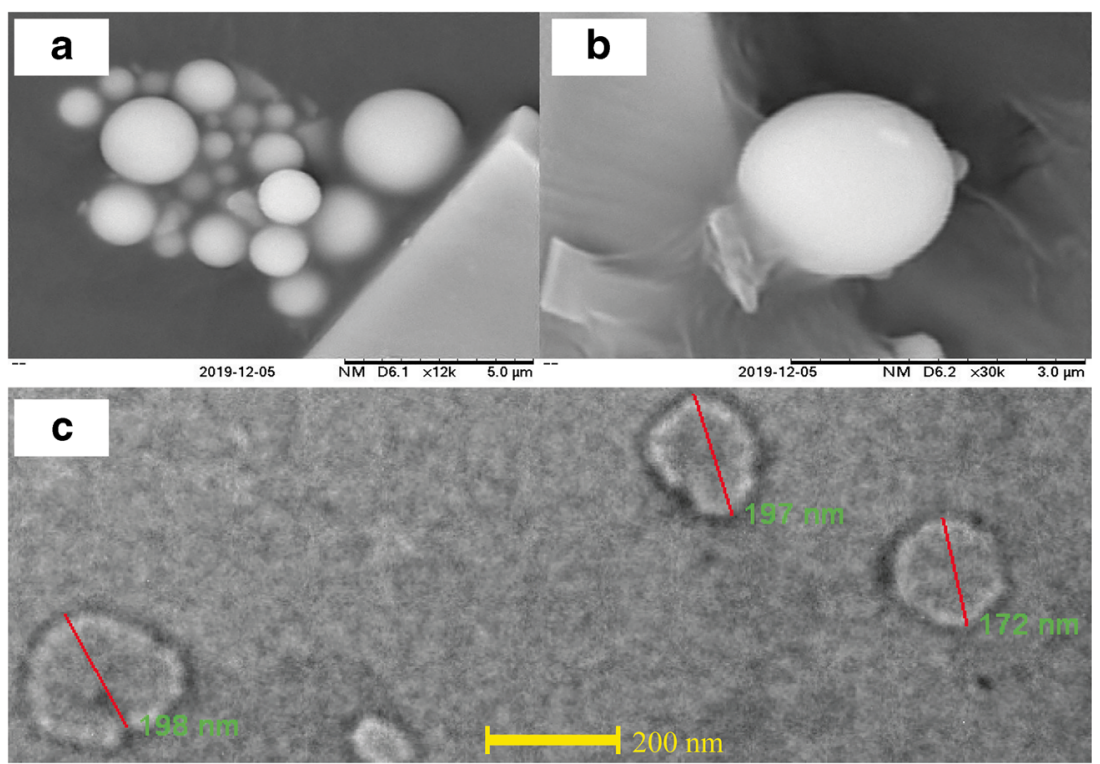

Fig. 4. SEM image of PALN1 at $\mathbf{a} \times 12,000, \mathbf{b} \times 30,000$, and HRTEM image of PALNs at $\mathbf{c} \times$ 7800

\section{Attenuated Total Reflection-Fourier Transform Infrared}

Figure 6 showed PEG 2000 characteristic peaks at $3409 \mathrm{~cm}^{-1}$ indicating intermolecular hydrogen-bonded hydroxyl group $(\mathrm{O}-\mathrm{H})$ asymmetric stretching. Peaks at $2945 \mathrm{~cm}^{-1}, 2884 \mathrm{~cm}^{-1}$, and $2860 \mathrm{~cm}^{-1}$ are assigned to $\mathrm{C}-\mathrm{H}$ symmetrical stretching. $\mathrm{C}-\mathrm{H}$ bending is observed at $2740 \mathrm{~cm}^{-1}$ (42). Peaks at $1240 \mathrm{~cm}^{-1}, 1146 \mathrm{~cm}^{-1}, 1099 \mathrm{~cm}^{-1}$, and $1059 \mathrm{~cm}^{-1}$ are assigned to C-O-C stretching $(43,44)$. Chitosan's broad peak at $3354 \mathrm{~cm}^{-1}$ and $3291 \mathrm{~cm}^{-1}$ are indexed to $\mathrm{NH}_{2}$ stretching vibration. Peaks at $1651 \mathrm{~cm}^{-1}$ and $1585 \mathrm{~cm}^{-1}$ are assigned to $\mathrm{N}-\mathrm{H}$ bending of primary amine. Peaks $1199 \mathrm{~cm}^{-1}$ and $1150 \mathrm{~cm}^{-1}$ are attributed to $\mathrm{C}-\mathrm{O}$ stretching of C-O-C. Two intense peaks at $1058 \mathrm{~cm}^{-1}$ and $1026 \mathrm{~cm}^{-1}$ indicate the presence of primary aliphatic amine stretching of $\mathrm{C}-\mathrm{N}$ overlapping with secondary cyclic alcohol stretching of $\mathrm{O}-\mathrm{H}^{1}(42,43,45)$. A peak at $894 \mathrm{~cm}^{-1}$ is attributed to the pyranoid ring of chitosan (46).

Lecithin' IR spectrum displays characteristic N-H group stretching at peak $3379 \mathrm{~cm}^{-1}$ (47). Symmetry stretching of C-
$\mathrm{H}$ for the cis-double bond is depicted at $3009 \mathrm{~cm}^{-1}$. Saturated aliphatic ester carbonyl stretching $(-\mathrm{C}=\mathrm{O})$ is represented at peak $1735 \mathrm{~cm}^{-1}$ (48). A strong, sharp peak at $1087 \mathrm{~cm}^{-1}$ shows a symmetric stretching of phosphate groups (42). The asymmetric stretchings of $\mathrm{P}=\mathrm{O}$ which overlapped with $\mathrm{P}-\mathrm{O}$ where both co-exist in phosphodiester group, together with $\mathrm{P}-\mathrm{O}-\mathrm{C}$ stretching, were at peaks $1238 \mathrm{~cm}^{-1}$ and $1062 \mathrm{~cm}^{-1}$ respectively. The peak at $968 \mathrm{~cm}^{-1}$ is attributed to $\mathrm{N}^{+}-\left(\mathrm{CH}_{3}\right)_{3}$ asymmetric stretching overlapped with $\mathrm{O}-\mathrm{P}-\mathrm{O}$ deformation (49). Out of plane bending of $\mathrm{HC}-\mathrm{CN}$ is depicted at $818 \mathrm{~cm}^{-1}$ (50).

Acyclovir IR spectrum shows intermolecular and intramolecular hydrogen-bonded hydroxyl group (O-H) stretchings at $3515 \mathrm{~cm}^{-1}$ and $3470 \mathrm{~cm}^{-1}$ (51), while $\mathrm{NH}_{2}$ symmetrical stretching is at $3438 \mathrm{~cm}^{-1}$ (52). Secondary amine stretching is at $3290 \mathrm{~cm}^{-1}$ (42). A peak at $3177 \mathrm{~cm}^{-1}$ is attributed to $\mathrm{N}-\mathrm{H}$ stretching overlapped with $\mathrm{O}-\mathrm{H}$ stretching (47). $\mathrm{C}-\mathrm{H}$ and $\mathrm{H}-\mathrm{C}-\mathrm{H}$ stretchings are represented at $2927 \mathrm{~cm}^{-1}$ and $2854 \mathrm{~cm}^{-1}$ (42). The presence of $\mathrm{C}=\mathrm{O}$ at $1708 \mathrm{~cm}^{-1}$, presence of $\mathrm{C}_{8}-\mathrm{H}$ together with ring vibration of

Table 5. Statistical Analysis Results of Entrapment Efficiency, Particle Size, and Zeta Potential

\begin{tabular}{|c|c|c|c|c|c|c|}
\hline \multirow[t]{2}{*}{ Parameter } & \multicolumn{2}{|c|}{ Drug EE (\%) } & \multicolumn{2}{|c|}{ Particle size $(\mathrm{nm})$} & \multicolumn{2}{|c|}{ Zeta potential $(\mathrm{mV})$} \\
\hline & Coefficient & $p$ value & Coefficient & $p$ value & Coefficient & $p$ value \\
\hline Intercept & 85.4405 & $<0.0001^{*}$ & 162.826 & $<0.0001^{*}$ & 28.0896 & $<0.0001^{*}$ \\
\hline$X_{1}$ & 3.5735 & $0.0003^{*}$ & 16.2333 & $0.0054^{*}$ & -3.5675 & $0.0050 *$ \\
\hline$X_{2}$ & -3.8271 & $0.0002 *$ & 18.3916 & $0.0028^{*}$ & 8.6821 & $<0.0001 *$ \\
\hline$X_{3}$ & -2.0429 & $0.0064 *$ & 16.7166 & $0.0047 *$ & -7.1571 & $<0.0001 *$ \\
\hline$X_{1} X_{2}$ & -2.0193 & $0.0315^{*}$ & 14.4667 & $0.0410 *$ & 0.4175 & 0.7481 \\
\hline$X_{1} X_{3}$ & 1.1877 & 0.1588 & -14.0668 & $0.0454 *$ & 1.8325 & 0.1860 \\
\hline$X_{2} X_{3}$ & -1.9454 & $0.0363 *$ & -15.65 & $0.0305^{*}$ & 2.0833 & 0.1395 \\
\hline$X_{1}^{2}$ & -6.9129 & $<0.0001^{*}$ & 17.3868 & $0.0178^{*}$ & 1.5143 & 0.2538 \\
\hline$X_{2}^{2}$ & -4.3391 & $0.0006^{*}$ & 26.7035 & $0.0021^{*}$ & 6.6986 & $0.0009 *$ \\
\hline$X_{3}^{2}$ & -0.1888 & 0.8044 & 47.3201 & $<0.0001^{*}$ & 1.8436 & 0.1739 \\
\hline
\end{tabular}

${ }^{*} p$ value less than 0.05 


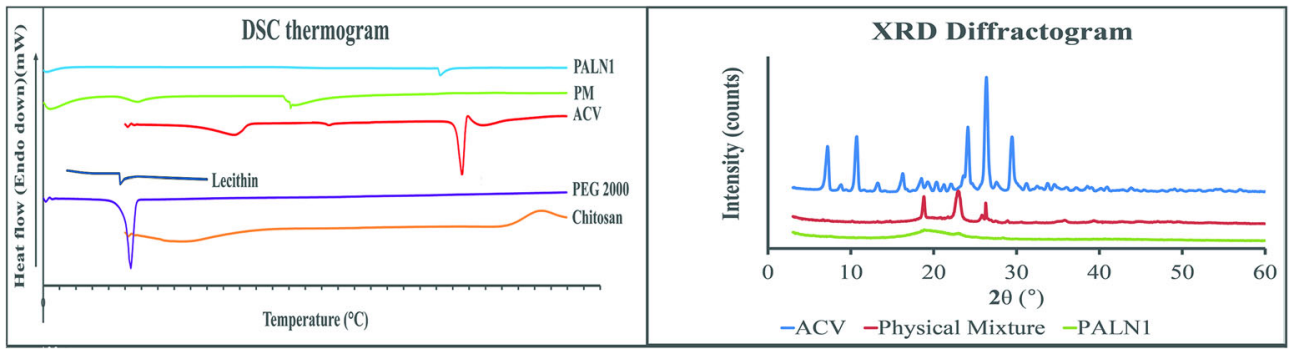

Fig. 5. Characterisation of PALN nanoparticles. a DSC thermogram of PALNs, physical mixture, ACV, lecithin, PEG 2000, chitosan; b XRD Diffractogram for PALNs

guanine, was shown at $1483 \mathrm{~cm}^{-1}$, while the presence of guanine structure was inferred at $1370 \mathrm{~cm}^{-1}$ (42).

The IR spectra of PM represent the combination of all characteristic peaks, such as $2884 \mathrm{~cm}^{-1}$ and $2860 \mathrm{~cm}^{-1}$ (PEG 2000); $3354 \mathrm{~cm}^{-1}$ and $3291 \mathrm{~cm}^{-1}$ (chitosan); $3379 \mathrm{~cm}^{-1}$ and $3009 \mathrm{~cm}^{-1}$ (lecithin); and $3470 \mathrm{~cm}^{-1}, 3438 \mathrm{~cm}^{-1}$, and $3177 \mathrm{~cm}^{-1}(\mathrm{ACV})$. The peaks showed very slight shifting $( \pm$ $5 \mathrm{~cm}^{-1}$ ), indicating no bonding interaction between drug and other formulation ingredients. PALN1 was observed that none of the ACV characteristic peaks emerged, indicating encapsulation of the drug.

\section{Stability Study of PALN1}

Table VI displays the particle size of PALN1 at different sampling time. The $t$ tests were conducted with a $p$ value higher than 0.05 for all tests suggested that there was an insignificant variation in PALN1 particle size on each sampling time as compared with 0th day's measurement. The obtained results were in agreement with a PALN1 zeta potential of $37.70 \pm 1.16 \mathrm{mV}$ which render the suspension stable by avoiding particle aggregation due to strong surface charge that repels each other. In brief, optimised formulations exhibit good physical stability for up to 60 days. There was no significant difference was observed $p<0.05$.

\section{In Vitro Drug Release}

Figure $7 \mathrm{a}$ and $\mathrm{b}$ showed ACV release profile in $\mathrm{pH} 1.2$ (SGF) and pH 6.4 (SIF) respectively. Various kinetic models were employed for a comprehensive understanding of drug release mechanisms from the optimised formulation. Table VII shows the values of correlation coefficient $\left(r^{2}\right)$ and releasing model constant $(k)$. Higuchi model showed the best fit with the highest $r^{2}$ value and can be concluded that the PALN formulation showed modified release. This model corresponds to the sustained release properties of lecithinchitosan nanoparticle. The drug release mechanism was identified based on the diffusion constant, $n$, from Korsmeyer-Peppas equation, as shown in Eq. (11). The mathematical adjustment of Eqs. (13) and (14) was obtained:

$\mathrm{Q}_{\mathrm{t}} / \mathrm{Q}_{\mathrm{CR}}=\mathrm{K}_{\mathrm{KP}} \mathrm{t}^{\mathrm{n}}$

$\log _{10}\left(\mathrm{Q}_{\mathrm{t}} / \mathrm{Q}_{\mathrm{CR}}\right)=\log _{10}\left(\mathrm{~K}_{\mathrm{KP}}\right) \mathrm{n} \log _{10} \mathrm{t}$ where $Q_{\mathrm{t}}$ and $Q_{\mathrm{CR}}$ indicate the amount of drug being released at time $t$ and after time $\infty$ respectively. $n$ represents the diffusional exponent and $K_{\mathrm{kp}}$ gives Korsmeyer release rate constant. Based on the equation, the slope of Korsemeyer-Peppas graph was the mechanism constant for Higuchi model. With $n$ values reported to be 0.6185 and 0.6103 for SGF and SIF, respectively, it was concluded that PALN1 was following Higuchi drug releasing model with non-Fickian transport.

\section{Study of Ex Vivo Drug Permeability}

Figure $7 \mathrm{c}$ shows the cumulative percentage of drug permeated against time. Table VIII shows that at the 10th hour, only $58 \%$ of the drug was permeated to the releasing media. The drug permeation profile had been prolonged due to the smaller porosity and thicker intestinal membrane compared with the dialysis membrane. The surface area of the intestine accommodating formulation was $5 \mathrm{~cm}^{2}$.

$$
\begin{aligned}
P_{\text {app }}\left(\mathrm{cm} \mathrm{s}^{-1}\right) & =\frac{1.1626 \mathrm{mg}}{10 \times 60 \times 60 \mathrm{~s}} \times \frac{1}{5 \mathrm{~cm}^{2} \times 1 \mathrm{mg} / \mathrm{cm}^{3}} \\
& =6.4589 \times 10^{-6} \mathrm{~cm} \mathrm{~s}^{-1}
\end{aligned}
$$

$$
\begin{gathered}
J_{s s}\left(m g \mathrm{~cm}^{-2} \mathrm{~s}^{-1}\right)=6.4589 \times 10^{-6} \mathrm{~cm} \mathrm{~s}^{-1} \times 1 \mathrm{mg} / \mathrm{cm}^{3} \\
=6.4589 \times 10^{-6} \mathrm{mg} \mathrm{cm}^{-2} \mathrm{~s}^{-1}
\end{gathered}
$$

$P_{\text {app }}$ of $6.4589 \times 10^{-6} \mathrm{~cm} / \mathrm{s}$ was a 3.2-fold improvement as compared with reported value of $0.12 \times 10^{-6}$ to $2.0 \times$ $10^{-6} \mathrm{~cm} \mathrm{~s}^{-1}$ (8). The optimised PALN formulation had the potential to be used in tablet formulation with improved drug intestinal permeability.

\section{CONCLUSION}

PEGylated lecithin-chitosan nanoparticle-encapsulated acyclovir were successfully formulated with particle size less than $200 \mathrm{~nm}$, optimum PDI, entrapment efficiency greater than $80 \%$, and with positive zeta potential value greater than +30 mV. SEM and HRTEM images showed the spherical structure of the nanoparticle. FTIR analysis with the diminishment of all ACV characteristic peaks in formulation 


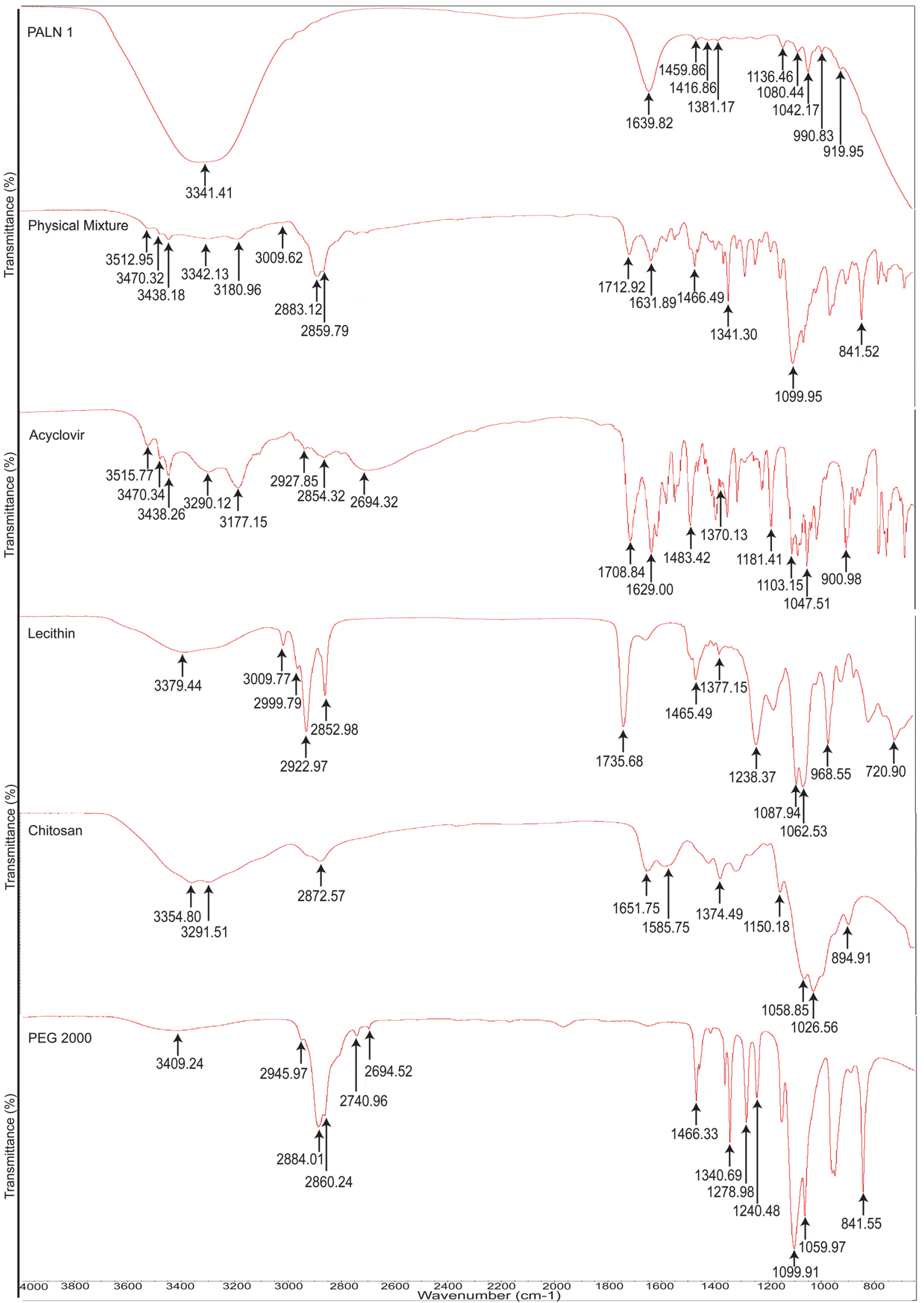

Fig. 6. Stacked spectra of ATR-FTIR from 4000 to $600 \mathrm{~cm}^{-1}$ for PALNs, physical mixture, acyclovir, lecithin, chitosan, and PEG 2000 
Table 6. Particle Size and Zeta Potential of PALNs at Each Sampling Time

\begin{tabular}{lll}
\hline Day & Particle size $(\mathrm{nm})$ & Zeta potential $(\mathrm{mV})$ \\
\hline 0th & $187.70 \pm 3.75$ & $37.94 \pm 0.33$ \\
15th & $193.80 \pm 5.73$ & $38.26 \pm 0.40$ \\
30th & $194.77 \pm 2.05$ & $38.22 \pm 0.33$ \\
45th & $184.37 \pm 4.00$ & $37.83 \pm 0.26$ \\
60th & $183.47 \pm 4.47$ & $37.32 \pm 0.29$ \\
\hline
\end{tabular}

spectrum indicates its encapsulation. DSC thermogram depicted a left shift, evidencing acyclovir's state changes from crystalline to amorphous property. The obtained results is further proved by the presence of a broad peak of PALN1 and diminishment of ACV crystalline peak in XRD diffractogram. In vitro release profile of ACV in nanoparticles had shown 24-h sustained release following Higuchi model with non-Fickian mechanism in both SGF and SIF. Ex vivo permeation study displayed a 3.2-fold improvement for acyclovir's apparent permeability. The formulation was stable up to 60 days from the aspect of particle size. The results demonstrated the ability of PEGylated lecithin-chitosan nanoparticles not only in providing high encapsulation of
Table 7. Coefficient of Determination $r^{2}$ and Releasing Model Constant $K$ for Drug Releasing Models

\begin{tabular}{llllll}
\hline Model & $\mathrm{pH} 1.2$ & & $\mathrm{pH} 6.4$ & \\
\cline { 2 - 3 } \cline { 5 - 6 } & $\begin{array}{l}\text { Coefficient of } \\
\text { determination } \\
r^{2}\end{array}$ & $\begin{array}{l}\text { Release } \\
\text { model } \\
\text { constant, } \\
K\end{array}$ & $\begin{array}{l}\text { Coefficient of } \\
\text { determination, } \\
r^{2}\end{array}$ & $\begin{array}{l}\text { Release } \\
\text { model } \\
\text { constant, } \\
K\end{array}$ \\
\hline $\begin{array}{l}\text { Zero order } \\
\text { First order }\end{array}$ & 0.6184 & 3.1424 & 0.5605 & 3.0729 \\
$\begin{array}{c}\text { Higuchi } \\
\text { model }\end{array}$ & 0.9339 & 0.2588 & 0.7999 & 1.3440 \\
$\begin{array}{c}\text { Korsmeyer- } \\
\text { Peppas } \\
\text { model }\end{array}$ & 0.3101 & 25.4563 & 0.9199 & 26.5229 \\
$\begin{array}{c}\text { Hixson- } \\
\text { Crowell } \\
\text { model }\end{array}$ & 0.0053 & 18.6351 & 0.2953 & 19.8312 \\
& & 0.0131 & 0.0032 & 0.0100 \\
\hline
\end{tabular}

The italicized is done to show the Nanoparticle release model is folloing Higuchi release model. It is done just to make it more visible

ACV and 24-h sustained release profile in both SGF and SIF, but also in enhancing the permeability of ACV. These findings suggested that PEGylated lecithin-chitosan

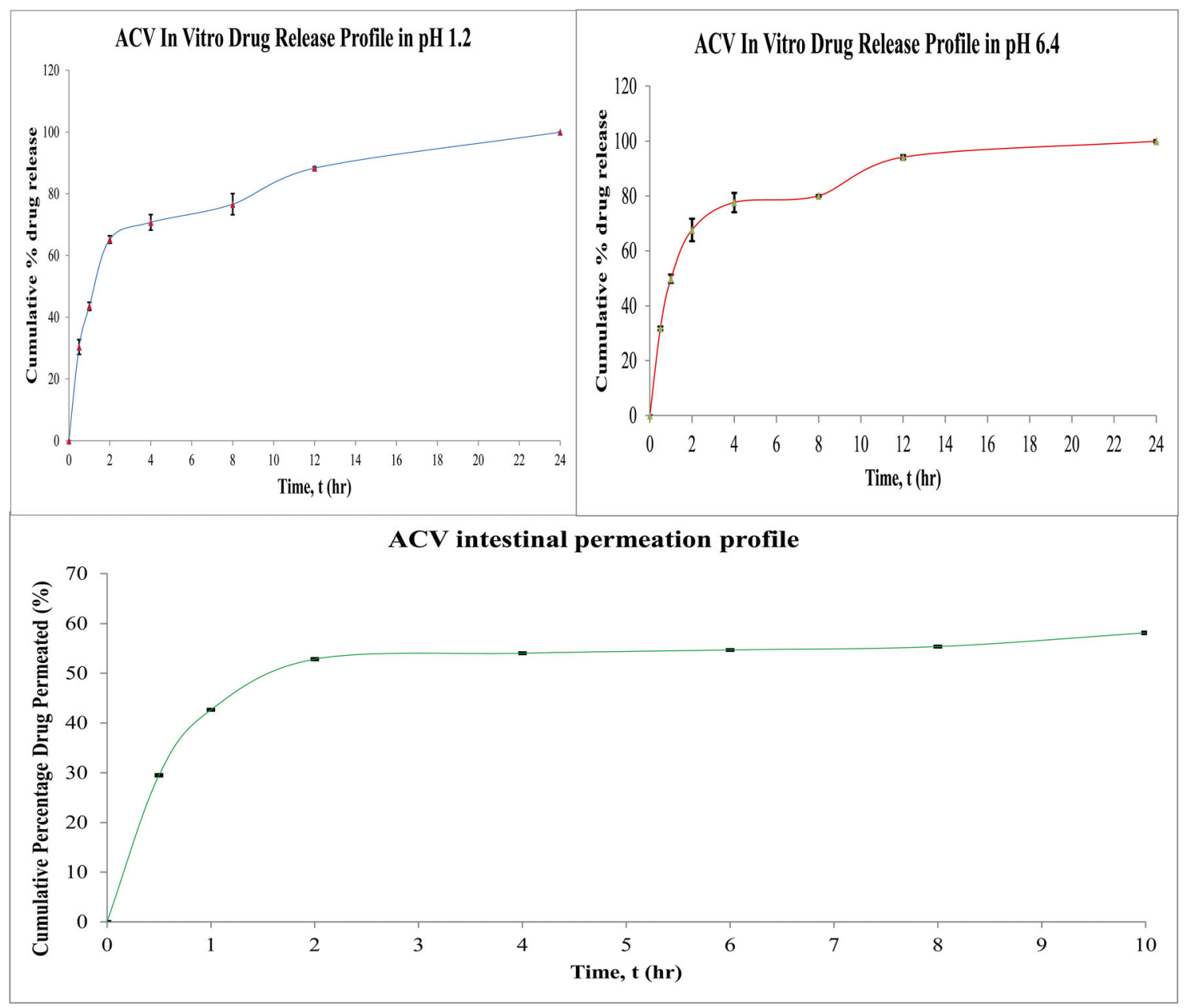

Fig. 7. $\mathrm{ACV}$ in vitro drug release profile in a $\mathrm{pH} 1.2, \mathbf{b} \mathrm{pH} 6.4$, and $\mathbf{c} \mathrm{ACV}$ intestinal permeation profile 
Table 8. Amount, Percentage of Acyclovir Permeated, and Apparent Permeability at Each Time Point

\begin{tabular}{llll}
\hline$t$ & Amount permeated & $\%$ permeated & Apparent permeability $\left(\mathrm{mg} / \mathrm{cm}^{2}\right)$ \\
\hline 0 & $0.0000 \pm 0.0000$ & $00.00 \pm 0.00$ & $0.0000 \pm 0.0000$ \\
0.5 & $0.5902 \pm 0.0009$ & $29.51 \pm 0.05$ & $0.1180 \pm 0.0002$ \\
1 & $0.8525 \pm 0.0003$ & $42.63 \pm 0.01$ & $0.1705 \pm 0.0001$ \\
2 & $1.0565 \pm 0.0010$ & $52.83 \pm 0.05$ & $0.2113 \pm 0.0002$ \\
4 & $1.0806 \pm 0.0003$ & $54.03 \pm 0.01$ & $0.2161 \pm 0.0001$ \\
6 & $1.0937 \pm 0.0001$ & $54.69 \pm 0.00$ & $0.2187 \pm 0.0000$ \\
8 & $1.1074 \pm 0.0002$ & $55.37 \pm 0.01$ & $0.2215 \pm 0.0000$ \\
10 & $1.1626 \pm 0.0016$ & $58.13 \pm 0.08$ & $0.2325 \pm 0.0003$ \\
\hline
\end{tabular}

nanoparticles may be used for drugs with poor aqueous solubility and permeability. Further, study on in vivo performance should be conducted to assess the improvement in oral bioavailability of ACV, as well as the applicability of this formulation on other BCS class III drugs.

\section{FUNDING}

The work was financially supported by the UMP internal grant (RDU 180371 and 180336).Abbreviations

\section{REFERENCES}

1. World Health Organization. Herpes simplex virus. 2017. https:// www.who.int/news-room/fact-sheets/detail/herpes-simplex-virus. Accessed 13 Dec 2019.

2. Jacobs GA, et al. Topical delivery of acyclovir and ketoconazole. Drug Deliv. 2016;23(2):631-41. https://doi.org/ 10.3109/10717544.2014.933283.

3. Seley-Radtke KL, Yates MK. The evolution of nucleoside analogue antivirals: a review for chemists and non-chemists. Part 1: early structural modifications to the nucleoside scaffold. Antivir Res. 2018;154:66-86. https://doi.org/10.1016/ j.antiviral.2018.04.004.

4. Maniya NH, Patel SR, Murthy ZVP. Controlled delivery of acyclovir from porous silicon micro- and nanoparticles. Appl Surf Sci. 2015;330:358-65. https://doi.org/10.1016/ j.apsusc.2015.01.053.

5. Nair AB, Attimarad M, Al-Dhubiab BE, Wadhwa J, Harsha S, Ahmed M. Enhanced oral bioavailability of acyclovir by inclusion complex using hydroxypropyl-beta-cyclodextrin. Drug Deliv. 2014;21(7):540-7. https://doi.org/10.3109/ 10717544.2013.853213.

6. Vaithianathan S, Haidar SH, Zhang X, Jiang W, Avon C, Dowling TC, et al. Effect of common excipients on the oral drug absorption of biopharmaceutics classification system class 3 drugs cimetidine and acyclovir. J Pharm Sci. 2016;105(2):9961005. https://doi.org/10.1002/jps.24643.

7. Shahsavari S, Farahani EV, Ardjmand M, Dorkoosh FA. Design and characterisation of Acyclovir loaded nanoparticles for controlled delivery system. Curr Nanosci. 2014;10:521-31. https://doi.org/10.2174/15734137113096660128.

8. Durai RD. Drug delivery approaches of an antiviral drug: a comprehensive review. Asian J Pharm. 2015;9:1-12. https:// doi.org/10.22377/ajp.v9i1.424.

9. Shin S, Kim TH, Jeong SW, Chung SE, Lee DY, Kim DH, et al. Development of a gastroretentive delivery system for acyclovir by $3 \mathrm{D}$ printing technology and its in vivo pharmacokinetic evaluation in Beagle dogs. PLoS One. 2019;14(5):1-17. https:// doi.org/10.1371/journal.pone.0216875.
10. Ghosal K, Adak S, Agatemor C, Praveen G, Kalarikkal N, Thomas S. Novel interpenetrating polymeric network based microbeads for delivery of poorly water soluble drug. J Polym Res. 2020;27(4):1-11. https://doi.org/10.1007/s10965-020-020776.

11. Wong CY, Al-Salami H, Dass CR. The role of chitosan on oral delivery of peptideloaded nanoparticle formulation. J Drug Target. 2017;26(7):551-62. https://doi.org/10.1080/ 1061186X.2017.1400552.

12. Tanner G, Yesiloz R, Vardar DO, Senyigit T, Ozer O, Degen $\mathrm{GH}$, et al. Evaluation of the cytotoxic and genotoxic potential of lecithin/chitosan nanoparticles. J Nanopart Res. 2014;16(2220):2-9. https://doi.org/10.1007/s11051-013-2220-2.

13. Lobato MD, Banderas LM, Goncalves LMD, Arévalo MF, Almeida AJ. Comparative study of chitosan- and PEG-coated lipid and PLGA nanoparticles as oral delivery systems for cannabinoids. J Nanopart Res. 2015;17(61):1-17. https://doi.org/ 10.1007/s11051-015-2875-y.

14. Wang F, Zhang M, Zhang D, Huang Y, Chen L, Jiang S, et al. Preparation, optimisation, and characterisation of chitosan coated solid lipid nanoparticles for ocular drug delivery. J Biomed Res. 2018;32(6):411-23. https://doi.org/10.7555/ JBR.32.20160170.

15. Ilk S, Saglam N, Özgen M. Kaempferol loaded lecithin/chitosan nanoparticles: preparation, characterisation, and their potential applications as a sustainable antifungal agent. Artif Cells Nanomed Biotechnol. 2017;45(5):907-16. https://doi.org/ 10.1080/21691401.2016.1192040.

16. Ruiz AGP, Ganem A, Corichi IMO, Sánchez JRG. Lecithinchitosan-TPGS nanoparticles as nanocarriers of (-)-epicatechin enhanced its anticancer activity in breast cancer cells. RSC Adv. 2018;8:34773-82. https://doi.org/10.1039/C8RA06327C.

17. Mahmood S, Mandal UK, Chatterjee B. Transdermal delivery of raloxifene $\mathrm{HCl}$ via ethosomal system: formulation, advanced characterisations and pharmacokinetic evaluation. Int J Pharm. 2018;542(1-2):36-46. https://doi.org/10.1016/ j.ijpharm.2018.02.044.

18. Mariyam M, Ghosal K, Thomas S, Kalarikkal N, Latha MS. Dendrimers: general aspects, applications and structural exploitations as prodrug/ drug-delivery vehicles in current medicine. Mini-Rev Med Chem. 2018;18(5):439-57. https:// doi.org/10.2174/1389557517666170512095151.

19. Nag OK, Awasthi V. Surface engineering of liposomes for stealth behavior. Pharmaceutics. 2013;5:542-69. https://doi.org/ 10.3390/pharmaceutics5040542.

20. Suk JJ, Xu Q, Kim N, Hanes J, Ensign LM. PEGylation as a strategy for improving nanoparticle-based drug and gene delivery. Adv Drug Deliv Rev. 2016;99:28-51. https://doi.org/ 10.1016/j.addr.2015.09.012

21. Dai Y, Xing H, Song F, Yang Y, Qiu Z, Lu X, et al. Biotinconjugated multilayer poly [D,L-lactide-co-glycolide]- lecithinpolyethylene glycol nanoparticles for targeted delivery of doxorubicin. J Pharm Sci. 2016;105:2949-58. https://doi.org/ 10.1016/j.xphs.2016.03.038.

22. Ways TMM, Lau WM, Khutoryanskiy VV. Chitosan and its derivatives for application in mucoadhesive drug delivery 
systems. Polymers. 2018;10(267):1-37. https://doi.org/10.3390/ polym 10030267.

23. Arya G, Das M, Sahoo SK. Evaluation of curcumin loaded chitosan/PEG blended PLGA nanoparticles for effective treatment of pancreatic cancer. Biomed Pharmacother. 2018;102:555-66. https://doi.org/10.1016/j.biopha.2018.03.101.

24. Alkholief M, Albasit H, Alhowyan A, Alshehri S, Raish M, Kalam MA, et al. Employing a PLGA-TPGS based nanoparticle to improve the ocular delivery of acyclovir. Saudi Pharm J. 2019;27(2):293-302. https://doi.org/10.1016/j.jsps.2018.11.011.

25. Sayed S, Habib BA, Elsayed GM. Tri-block co-polymer nanocarriers for enhancement of oral delivery of felodipine: preparation, in vitro characterisation and ex vivo permeation. $\mathbf{J}$ Liposome Res. 2018;28(3):182-92. https://doi.org/10.1080/ 08982104.2017.1327541.

26. Raut S, Bhadoriya SS, Uplanchiwar V, Mishra V, Gahane A, Jain SK. Lecithin organogel: a unique micellar system for the delivery of bioactive agents in the treatment of skin aging. Acta Pharm Sin B. 2012;2(1):8-15. https://doi.org/10.1016/ j.apsb.2011.12.005.

27. Tan Q, Liu W, Guo C, Zhai G. Preparation and evaluation of quercetin-loaded lecithin-chitosan nanoparticles for topical delivery. Int J Nanomedicine. 2011;6:1621. https://doi.org/ 10.2147/IJN.S22411.

28. Chhonker YS, Prasad YD, Chandasana H, Vishvkarma A, Mitra K, Shukla PK, et al. Amphotericin-B entrapped lecithin/ chitosan nanoparticles for prolonged ocular application. Int $\mathrm{J}$ Biol Macromol. 2015;72:1451-8. https://doi.org/10.1016/ j.ijbiomac.2014.10.014.

29. Ou H, Cheng T, Zhang Y, Liu J, Ding Y, Zhen J, et al. Surfaceadaptive zwitterionic nanoparticles for prolonged blood circulation time and enhanced cellular uptake in tumor cells. Acta Biomater. 2018;65:339-48. https://doi.org/10.1016/ j.actbio.2017.10.034.

30. Halabalová V, Šimek L. A study of the interaction between chitosan and poly (ethylene glycol) by viscosity method. Int J Polym Anal Charact. 2006;11(3):185-95. https://doi.org/10.1080/ 10236660600658336.

31. Stepniewski M, Pasenkiewicz-Gierula M, Róg T, Danne R, Orlowski A, Karttunen M, et al. Study of PEGylated lipid layers as a model for PEGylated liposome surfaces: molecular dynamics simulation and Langmuir monolayer studies. Langmuir. 2011;27(12):7788-98. https://doi.org/10.1021/la200003n.

32. Mahmood S, Mandal UK. Morphological characterization of lipid structured nanoparticles by atomic force microscopy while minimizing the formation of failed artefacts. Curr Nanosci. $2017 ; 2$ (1):24-32. https://doi.org/10.2174/ 2405461502666170329100007.

33. Liu L, Zhou C, Xia X, Liu Y. Self-assembled lecithin/chitosan nanoparticles for oral insulin delivery: preparation and functional evaluation. Int J Nanomedicine. 2016;11:761. https:// doi.org/10.2147/IJN.S96146.

34. Cruje C, Chithrani DB. Polyethylene glycol functionalized nanoparticles for improved cancer treatment. Rev Nanosci Nanotechnol. 2014;3(1):20-30. https://doi.org/10.1166/ rnn.2014.1042.

35. Hu C, Tian F, Zheng Y, Tan CSY, West KR, Scherman OA. Cucurbit [8] uril directed stimuli-responsive supramolecular polymer brushes for dynamic surface engineering. Chem Sci. 2015;6(9):5303-10. https://doi.org/10.1039/C5SC01496D.

36. Rana S, Barick K, Shetake NG, Verma G, Aswal V, Panicker L, et al. PEG functionalized luminescent lipid particles for cellular imaging. Chem Phys Lett. 2016;659:225-9. https://doi.org/ 10.1016/j.cplett.2016.07.038.

37. Mahmood S, Hilmi NN, Husain NK, Chatterjee B, Mandal UK. Differential scanning calorimetric characterisation of pharmaceutical powder blend uniformity in a laboratory-scale V-blender. Powder Technol. 2016;287:152-9. https://doi.org/ 10.1016/j.powtec.2015.10.004

38. Nartowski KP, Karabin J, Morritt AL, Nowak M, Fábián L, Karolewicz B, et al. Solvent driven phase transitions of acyclovir-the role of water and solvent polarity. Crystengcomm. 2019;21(13):2180-92. https://doi.org/10.1039/C8CE01814F.
39. Paliwal S, Tilak A, Sharma J, Dave V, Sharma S, Verma K, et al. Flurbiprofen-loaded ethanolic liposome particles for biomedical applications. J Microbiol Methods. 2019;161:18-27. https:// doi.org/10.1016/j.mimet.2019.04.001.

40. Thomas LC, Schmidt SJ, Lee JW, Lu Y. "Apparent melting": a new approach to characterizing crystalline structure in pharmaceutical materials. 2018. https://www.tainstruments.com/ dsc-characterization-of-crystalline-foods-pharmaceuticalsapparent-melting-part-2-of-3/. Accessed 10 Dec 2019.

41. Sammour RM, Taher M, Chatterjee B, Shahiwala A, Mahmood S. Optimization of Aceclofenac Proniosomes by using different carriers, part 1: development and characterization. Pharmaceutics. 2019 Jul;11(7):350. https://doi.org/10.3390/ pharmaceutics 11070350 .

42. Talari ACS, Martinez MAG, Movasaghi Z, Rehman S, Rehman IU. Advances in Fourier transform infrared (FTIR) spectroscopy of biological tissues. Appl Spectrosc Rev. 2017;52(5):456506. https://doi.org/10.1080/05704928.2016.1230863.

43. Chauhan JK, Kumar M, Yadav M, Tiwari T, Srivastava N. Effect of $\mathrm{NaClO} 4$ concentration on electrolytic behaviour of corn starch film for supercapacitor application. Ionics. 2017;23(10):2943-9. https://doi.org/10.1007/s11581-017-2136-4.

44. Kamnev AA, Tugarova AV, Dyatlova YA, Tarantilis PA, Grigoryeva OP, Fainleib AM, et al. Methodological effects in Fourier transform infrared (FTIR) spectroscopy: implications for structural analyses of biomacromolecular samples. Spectrochim Acta A. 2018;193:558-64. https://doi.org/10.1016/ j.saa.2017.12.051.

45. Kumar S, Shukla A, Baul PP, Mitra A, Halder D. Biodegradable hybrid nanocomposites of chitosan/gelatin and silver nanoparticles for active food packaging applications. Food Packag Shelf Life. 2018;16:178-84. https://doi.org/ 10.1016/j.fpsl.2018.03.008.

46. Liao B, Sun W-Y, Guo N, Ding S-L, Su S-J. Equilibriums and kinetics studies for adsorption of $\mathrm{Ni}$ (II) ion on chitosan and its triethylenetetramine derivative. Colloids Surf A Physicochem Eng Asp. 2016;501:32-41. https://doi.org/10.1016/ j.colsurfa.2016.04.043.

47. Mudunkotuwa IA, Al Minshid A, Grassian VH. ATR-FTIR spectroscopy as a tool to probe surface adsorption on nanoparticles at the liquid-solid interface in environmentally and biologically relevant media. Analyst. 2014;139(5):870-81. https://doi.org/10.1039/C3AN01684F

48. Guo Q, Ai L, Cui SW. Fourier transform infrared spectroscopy (FTIR) for carbohydrate analysis. In: Methodology for Structural Analysis of Polysaccharides. Cham: Springer; 2018. p. 6971. https://doi.org/10.1007/978-3-319-96370-9_9.

49. Han Y, Han L, Yao Y, Li Y, Liu X. Key factors in FTIR spectroscopic analysis of DNA: the sampling technique, pretreatment temperature and sample concentration. Anal Methods. 2018;10(21):2436-43. https://doi.org/10.1039/ C8AY00386F.

50. Eșme A, Sağdınç S. Conformational, spectroscopic (FT-IR, FTRaman, and UV-Vis), and molecular docking studies of N-(2hydroxyethyl) succinimide. J Mol Struct. 2019;1195:451-61. https://doi.org/10.1016/j.molstruc.2019.06.019.

51. Kumar S, Kumar BCV, Revanasiddappa HD. Crystal structure, Hirshfeld analysis and HSA interaction studies of $\mathrm{N}^{\prime}-[(\mathrm{E})-(5-$ bromothiophen-2-yl) methylidene]-3-hydroxynaphthalene-2carbohydrazide. J Mol Struct. 2019;1189:343-51. https://doi.org/ 10.1016/j.molstruc.2019.03.070.

52. Badawy ME, Taktak NE, Awad OM, Elfiki SA, El-Ela NE. Preparation and characterisation of biopolymers chitosan/alginate/gelatin gel spheres crosslinked by glutaraldehyde. J Macromol Sci B. 2017;56(6):359-72. https://doi.org/10.1080/ 00222348.2017.1316640.

Publisher's Note Springer Nature remains neutral with regard to jurisdictional claims in published maps and institutional affiliations. 